\title{
New Start of Nokia
}

Fakhrutdinova E.V.a

Fakhrutdinov R.M. ${ }^{\mathrm{b}}$

Kolesnikova J.S.c

Yurieva O.V. ${ }^{d}$

acd Kazan Federal University, Institute of Management, Economics and Finance, Kazan, 420008, Russia

Email: hulia_k@mail.ru

b Graduate School of Management is St. Petersburg State University, Volkhovskiy Per.3 St.Petersburg 199004, Russia

\section{Doi:10.5901/mjss.2015.v6n1s3p61}

\section{Abstract}

Microsoft will take over Nokia's Devices and Services business, which includes both Smart Devices and Mobile Devices. In other words: The Lumia, Asha and X series are now all under Microsoft's umbrella. Design teams, supply chain, accessories, employees, developer relations and most of Nokia's manufacturing plants and testing facilities are also on Microsoft's side, as are most of the company's services like MixRadio, Store and more. Here, Nokia's mapping entity, is considered a separate business and isn't included as part of the deal, but Microsoft has agreed to a 10-year licensing agreement. On the one hand, Nokia's decision to sell its mobile phone business to Microsoft is a Finnish tragedy. At Nokia's best times, this giant contributed a quarter of Finland's economic growth for past 10 years: it paid 23\% of Finland's corporate taxes. On the other hand, getting out of the mobile phone business sector is a probable blessing for Nokia. Life is tough nowadays for second-tier smartphone companies. Nokia's global market share in the mobile phone market has dropped to 14 percent (from 19.9 percent a year ago, according to Gartner). The revenue of the company brings in from its devices and services division is down by more than half since 2008. This paper is aimed to show why Nokia had to be saved by someone external, both from the technological and financial point of view.

Keywords: acquisition, mobile phone business, revenues, smartphone, loss, technology

\section{Introduction}

In September 2013, Nokia announced that an agreement is reached with Microsoft in which the latter would purchase substantially all of Nokia's Devices \& Services business. This may be the primary landmark for the Finnish Company [1].

Nokia is a Finnish multinational corporation with headquarters in Espoo, Finland and which used to be a leader in mobile communications information technology. Nokia's technological and design innovations have made its brand one of the most recognized in the world and its products have become an integral part of the people lives around the world.

The main products it offers are not only mobile phones and portable IT devices, but also Internet services including applications, games, music, media and messaging and free-of-charge digital map information and navigation services. Their aim is to deliver differentiated and innovative products to people around the world.

Through its software platforms, Series 30 and Series 40, Nokia has also been developing markets around the world, connecting even more people to their first Internet and application experience and providing consumers with powerful and very affordable mobile products, particularly in emerging markets.

\section{Theory}

Nokia's share in the global Smartphone market has shown a huge decline in the past couple of years. The problem began with the introduction of the iPhone in 2007, which set a new era in the market. The Finish Company did not recognize that the iPhone release and the introduction of the App Store, as well as Google's Android ecosystem would attract more attention than Nokia products and its operating system - Symbian.

In order to return market leadership, in February 2011 Nokia entered into partnership with Microsoft. Stephen Elop, CEO of Nokia, referred to the operating system Symbian as a burning platform in a memo to his staff in the beginning of 2011. 
The company tried to create a new identity by entering the cooperation with Microsoft and introducing the series of Smartphone called Nokia Lumia [2].

The partnership was divided into three broad areas:

1. Nokia is responsible for mapping, navigation and certain location-based services integrated in the Windows Phone ecosystem. Nokia will build innovation in areas like hardware design and language support. Microsoft will provide Bing search services as well as productivity, advertising, social media, gaming and a variety of other services.

2. Microsoft has the right to receive a running royalty from Nokia for Windows Phone platform [3].

3. In recognition of the unique corporation between Nokia and Microsoft, Nokia will receive payments measured in billions of dollars.

A very important point is the distribution of the profits. The three broad areas mentioned before create the impression that both companies are, in effect, paying each other something and sharing the profits [4]. The Nokia Lumia definitely represents the knowledge and technology of both companies.

The market reaction to Mr. Elop's announcement had consequences and influenced immediately Nokia's and Microsoft's stock prices. Both companies have suffered a relative decline at the end of 2010. In the following month we can see a smaller recover. After the announcement Nokia's stock prices decreased from 7,56 Euro to 6,77 Euro few days after[5].

Although Nokia found with Microsoft a strong partner, the company is also suffering from the innovative competitors. In the fourth quarter of the year 2012 the company listed his first loss since 1986. The fourth quarter was showing a loss of 492 million $\$[6]$.

\section{Results}

Now, I will analyse from an investor point of view, the reasons behind the problems Nokia had to tackle. To do so, I will go through 3 stages: a) Income Statement analysis, b) Financial structure analysis, and c) Performance in the Stock Exchange [7].

\subsection{Income Statement analysis}

The first thing the investor needs to know is the Nokia's expenditures and revenues, and the easiest way to do so is to analyse the income statement of the company. However, it is not only important the performance of this year, but also the previous ones in order to have a greater overview, and in that way, see the reasons of the bankruptcy.

It is shown, that, although gross margin has remained positive, it has been reduced by more than $36 \%$, due to a large decrease in sales, which has been greater than the decrease of costs. This can be explained because Nokia did not answer accurately to the arising of smartphones while its competitors did (Samsung, Apple, HTC, etc.).

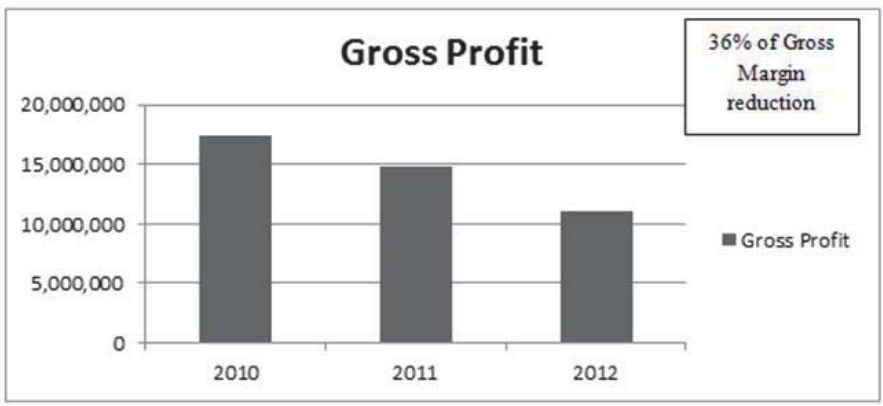

Fig.1 Gross Profit of Nokia [8]

However, we need to include all operating expenses such as selling general and administrative and research and development. Taking into account these additional costs, the net income is greatly loss-making during the last 2 years as can be seen in the following chart. One of the reasons we can find is that financial crisis hit mobile phones companies. Nevertheless, if we compare it with other firms in the field, we realise that this is not a true reason, because while Nokia was suffering from net income losses $(5,000,000 \$)$, Apple reached its best results ever $(41,733,000 \$)$. 


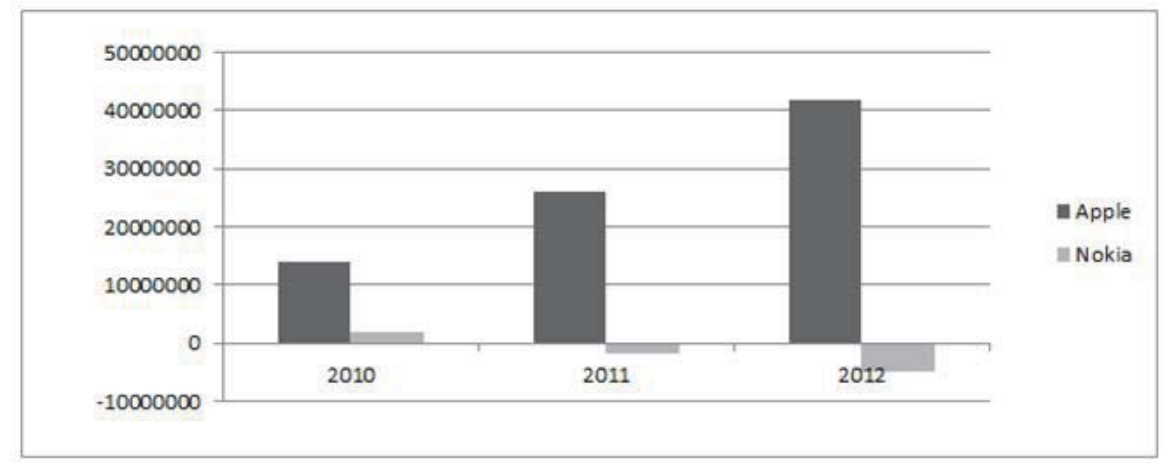

Fig. 2. Net Income (2014): Nokia \& Apple [9]

\subsection{Economic and financial analysis}

The Balance Sheet is another way to see the financial and economic situation of Nokia, and to do so we will go through different analysis.

\subsubsection{Working capital}

The working capital can help us a lot when analysing the performance of any company. There, we realise that the equilibrium in the company's structure has remained over the history of the firm. Nevertheless, we must mention that the working capital, that is, what ensures that the Nokia will successfully deal with payments, has been reduced for 2 reasons:

- There has been a huge increase of both long-term and short-term debt due to large investment carried out by Nokia. While debt represented 63\% in 2010, it signified 73\% in 2012.

- The equity has been reduced 9 million\$ in only 2 years which might be a sign that investors are not confident about its future, and consequently, they have disinvested in the company.

Table 1: Working Capital Dynamics [10]

\begin{tabular}{|l|c|c|c|}
\hline Working Capital & 2010 & 2012 & $\%$ \\
\hline Non-Current Assets & $\$ 13928000,00$ & $\$ 10307000,00$ & $-26,0 \%$ \\
\hline Current Assets & $\$ 36417000,00$ & $\$ 27526000,00$ & $-24,4 \%$ \\
\hline Equity & $\$ 19298000,00$ & $\$ 10628000,00$ & $-44,9 \%$ \\
\hline Long-Term & $\$ 8942000,00$ & $\$ 9548000,00$ & $6,8 \%$ \\
\hline Short-Term & $\$ 23531000,00$ & $\$ 19310000,00$ & $-17,9 \%$ \\
\hline
\end{tabular}

\subsubsection{Ratios}

In the figure below, it have been calculated some ratios because sometimes an overview to Income Statement and Balance Sheet can make things look what they are not. The conclusions we take out from them are:

- The profitability of Stockholder Equity (e) has been about $-65 \%$. This shows that the company's economy is dramatic.

- This $\%$ comes from an operative profit of $163 \%$ and a financial leverage of $-230 \%$. This tells us that the activity performed by Nokia was profitable since the operative profit is positive. However, the company went into huge debts which have put the company into big troubles.

- We have not been able to see this debt problem in the working capital analysis because the current assets were enough to cover the debts. We can conclude that liabilities are behind Nokia's problems.

- From the point of view the ratios, the situation of Nokia is extremely weak. 
Table 2: Financial Ratios [11]

\begin{tabular}{|c|c|c|c|c|}
\hline \multicolumn{5}{|c|}{ Ratios table } \\
\hline MB & 54408000 & & $I^{\star}(1-\mathrm{t})$ & 40000000 \\
\hline MBP & 1,368 & & FALP & 9548000 \\
\hline VPM & 10309414,40 & & $\mathrm{i}$ & 4,189 \\
\hline V-VPM & 29474585,60 & & $\mathrm{r}-\mathrm{i}$ & $-2,551$ \\
\hline BAll & 40309000 & & FP & 10628000 \\
\hline BAldl & 38799000 & & FALP/FP & 0,898 \\
\hline Margin & 0,975 & & $\mathrm{r}-\mathrm{i}){ }^{\star}$ FALP/FP & $-2,292$ \\
\hline Rotation & 1,680 & $\mathrm{e} 1$ & $-0,654$ \\
\hline $\mathrm{r}$ & 1,638 & $\mathrm{e}$ & $-0,65$ \\
\hline
\end{tabular}

\subsection{Performance in Stock Exchange}

The final thing we are going to do is an analysis taking information from the Stock Exchange. That is why; we will speak briefly about some key statistics:

- Market value may be the most important figure, and in this case, is about 25,800 million of dollars, and although it may sound a lot, if we compare it with Apple (477,830 millions) or Samsung (86,070 millions), Nokia's market value might be seen as low.

- The pay-back is other fundamental information that can help the investor. This concept, tells us about the time it requires to recover the amount invested. For Nokia, we need 46.47 years to recover the investment. However, the comparison is bad for Nokia because its competitors Apple (12.14) and Samsung overtake the Finnish company by far.

Finally, it may be interesting an analysis of the performance Nokia had in the Stock Exchange in terms of the share-price. Firstly, we can see a constant price around 15€ per share during 2009 because in most annual results, Nokia market share in all mobile phones, and in smartphones, was very stable [12]. This was in line with the industry growth number. If Nokia was below the industry overall growth, then its market share would decrease, and if Nokia performed better than its competitors, then Nokia's market share would gain to compensate it. This is a usual thing in the Stock Exchange. During that year Nokia's smartphones grew 36\% which can be thought as a good result, but it is not so good when the industry grew $75 \%$ on average [12]. And of course, if you grow less than the rest, you will lose market share. Apparently, Nokia's share price did not suffer from those disappointing sales.

Nevertheless, the situation worsened in 2010. Company's smartphones market share fell dramatically to 30\% in the third quarter, and another $28 \%$ the fourth one. Now, markets realise about these problems after carrying out an analysis similar to the one we have done previously. That year shares' price fell from $15 €$ to $12 €$ [12]. The reason behind this market share loss is the high competence coming basically from Apple and Samsung. To face it, Nokia tried to launch a new smartphone called "Ovi" with no success what made sales to continue falling not only in 2010, but also, in 2011 and in 2012.

Nokia's shares are depicted on Figure 1.

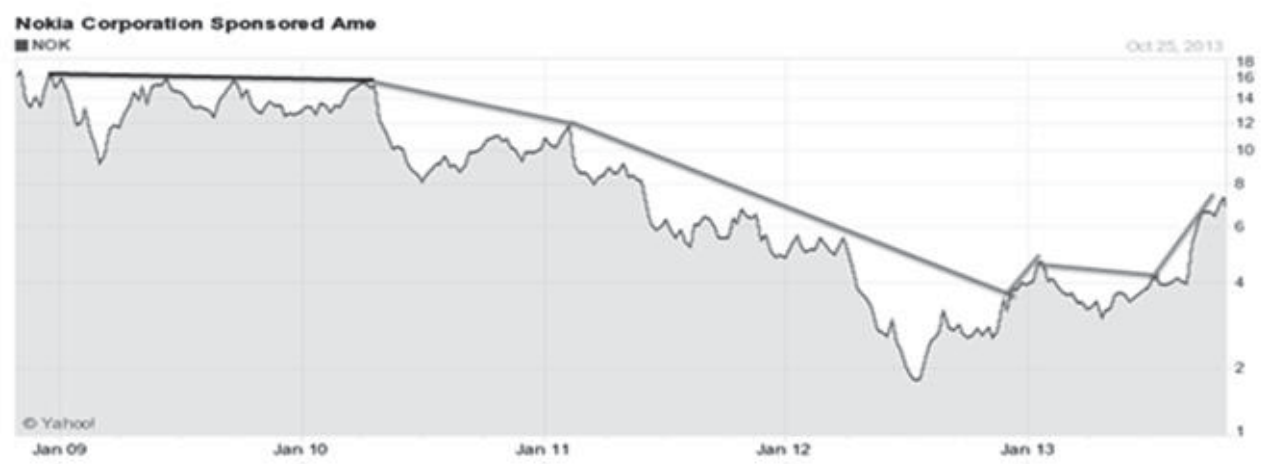

Fig. 3. Nokia's shares (2009-2013) [13] 
After three dramatic years, Nokia's results kept worsening as investors lost their confidence in the phone company. However, we see a timid share price increase in the early 2013 because of the first rumours about the purchase of Nokia by a Chinese company. As it did not succeed, Nokia let the market down, and lost what it had gained.

Finally, Microsoft decided to buy Nokia which came as a surprise to the market, which is shown in the chart moving share price from $4 €$ to $8 €$.

\section{Conclusions}

On the one hand, Nokia's decision to sell its mobile phone business to Microsoft is a Finnish tragedy. At Nokia's best times, this giant contributed a quarter of Finland's economic growth for past 10 years: it paid 23\% of Finland's corporate taxes [14].

On the other hand, getting out of the mobile phone business sector is a probable blessing for Nokia. Life is tough nowadays for second-tier smartphone companies. Nokia's global market share in the mobile phone market has dropped to 14 percent (from 19.9 percent a year ago, according to Gartner). The revenue the company brings in from its devices and services division is down by more than half since 2008. For sure, Nokia is not on the list of top smartphone sellers anymore. Analysts say, this deal with Microsoft means only one thing - the end of an era in mobile devices. BlackBerry and HTC are also at risk of being swept away by this shift, and the argument could be made that Nokia's strategic retreat should inspire some envy in their boardrooms.

The struggle against Apple and Google is now Microsoft's problem. It makes a certain amount of sense for Microsoft to bring Nokia in-house as it chooses this fight, given that Nokia phones already make up over 80 percent of the Windows phones worldwide. But even if Windows Phone recently surpassed BlackBerry as the world's third most popular mobile operating system, becoming a second OS seems very non-realistic. In the second quarter of this year, 8.7 million Windows phones shipped worldwide, compared to 31.7 million iPhones and 187.4 million Android phones, according to IDC. Microsoft apparently plans to do its best Apple impersonation, abandoning a more Google-like strategy of licensing its smartphone operating system to other companies. This is a tough sell; skepticism about the deal drove Microsoft stock prices down almost 2 percent on the stock market [15].

Nokia, meanwhile, will piece together a more modest, perhaps more sustainable future as a networking, mapping, and patent-licensing company. "They have the chance to continue investing in the businesses where they make money," said Francisco Jeronimo, an analyst at IDC.

These are some directions of common partnership of these two giants [16]:

\section{Networking}

The biggest part of the company is now NSN, which makes networking and telecommunications equipment. NSN already makes up 45 percent of the company's sales and seemed set to surpass the devices business this year. "Nokia Siemens Networks has a future in the network equipment world, with a streamlined operation and a second position in a nowconcentrated and -stable market," Pierre Ferragu, an analyst at Sanford C. Bernstein, told Bloomberg News in July, when Nokia bought out Siemens, its partner in the networking business.

\section{Mapping \& Patents}

Nokia is also hanging onto its mapping business, HERE, which makes up about 4 percent of the company's sales. It's interesting that Microsoft didn't acquire this aspect of Nokia's business, given the hunger for mapping companies shown by Apple, which acquired four mapping companies this year, and Google, which recently spent \$1.1 billion for Waze, the Israeli crowd-sourced traffic application. Instead, Microsoft and Nokia reached a cross-licensing agreement on patents that will allow HERE to use Microsoft patents. Microsoft is also paying Nokia for a four-year license to use the mapping platform.

Both the networking and mapping businesses are profitable, according to the company's internal measure of operating income. The devices business is not even close. In shedding the devices business, Nokia will be getting rid of over half of the costs it says it lays out to generate revenue-and about 32,000 employees. So, Nokia's future is smaller, but, probably, brighter [17]. 


\section{References}

Nokia sold to Microsoft its mobile phone business. Expansion URL: www.expansion.com/2013/11/19/empresas/digitech/ 1384882225.html (Accessed on the 14th of August, 2014).

Nokia and Microsoft Announce Plans for a Broad Strategic Partnership to Build a New Global Mobile Ecosystem. Microsoft URL: www.microsoft.com/en-us/news/press/2011/feb11/02-11partnership.aspx (Accessed on the 5th of August, 2014).

Fakhrutdinova E.V., Kirshin I. A., Kolesnikova J.S., Salyakhov E.F. The influence of cross-country technological transfer on economic profit formation // Middle East Journal of Scientific Research. Volume 17, Issue 12, 2013. pp. 1632-1634.

Kirshin I.A., Gareev B.R. Theory of constraints in value based cost management // World Applied Sciences Journal (Economics, Management and Finance). Volume 27, 2013. pp. 102-106.

Kirshin I.A. 2014. Modelling the long-term trend of accumulation of knowledge // Life Science Journal. Volume 11(6s), pp. 482 - 486.

Fakhrutdinova E.V, Kolesnikova J.S, Yurieva O.V, Kamasheva A.V. The commercialization of intangible assets in the information society // World Applied Sciences Journal. Volume 27, Issue 13, 2013. pp. 82-86.

Analyzing Business in Three Steps. Taringa URL: www.taringa.net/posts/economia-negocios/3153474/Como-analizar-una-empresa-entres-pasos-y-entender-si-puede.html (Accessed on the 14th of August, 2014).

Income Statement. Yahoo Finance URL: www.finance.yahoo.com/q/is?s=NOK+Income+Statement\&annual (Accessed on the 16th of August, 2014).

Income Statement Comparison. Yahoo Finance URL: www.finance.yahoo.com/q/is?s=NOK+Income+Statement\&annual (Accessed on the 20th of August, 2014).

Balance Sheet. Yahoo Finance URL: www.finance.yahoo.com/q/bs?s=NOK+Balance+Sheet\&annual (Accessed on the 25th of August, 2014).

Cash Flow. Yahoo Finance URL: finance.yahoo.com/q/cf?s=NOK+Cash+Flow\&annual (Accessed on the 25th of August, 2014).

Nokia in first loss to date. BBC URL: www.bbc.co.uk/news/business-18917906 (Accessed on the 25th of August, 2014).

Nokia Annual report on form 20-F 2012. Nokia URL: www.company.nokia.com/sites/default/files/download/form20-f-12-pdf.pdf (Accessed on the 25th of August, 2014).

Nokia - Espana. Nokia URL: www.nokia.com/es-es/?cid=nokiacom-fw-src-na-brand-home-google-es-es-1todtmxa382a6 (Accessed on the 29th of August, 2014).

Nokia falls into the arms of Microsoft. The Economist URL: www.economist.com/blogs/newsbook/2011/02/mobile_handset-makers (Accessed on the 30th of August, 2014).

For Microsoft and Nokia, Difficult Choices After Smartphone Deal. NY Times URL: www.nytimes.com/2011/02/18/technology/microsoftnokia.html?_r=0 (Accessed on the 30th of August, 2014).

Technical Analysis. Yahoo Finance URL: finance.yahoo.com/q/ta?s=NOK+Basic+Tech. (Accessed on the 26th of August, 2014). 